103 CASE REPORT: USE OF A PATIENT CONTROLLED DEVICE FOR DELIVERY OF BOLUS DOSES OF INTRATHECAL ANALGESIA IN CANCER RELATED PAIN UNRESPONSIVE TO CONVENTIONAL PAIN MANAGEMENT

Tarah Cullen, Miriam Colleran. HSE

10.1136/spcare-2020-PCC.123

Intrathecal analgesia is being used more frequently for patients with cancer pain unresponsive to regular treatments. In this case patient controlled intrathecal analgesia was used in a setting where the patient's pain was severe and unrelenting despite maximum tolerated doses of numerous analgesics, radiotherapy and nerve blocks. With the addition of the MyPTM device the patient's symptoms were markedly improved and as a result some baseline analgesia could be reduced. Though the intervention was relatively successful it did result in bothersome side effects and also brought with it new and challenging difficulties in relation to opioid management for us, the treating team to overcome.

\section{THE PAIN OF WAITING FOR PAIN RELIEF: USING E- PRESCRIBING DATA TO STUDY SUBCUTANEOUS SYRINGE DRIVER DELAYS IN A LARGE TEACHING HOSPITAL IN ENGLAND}

Sarah D Freshwater, Jon Tomas, Stephanie Shayler. Queen Elizabeth Hospital, Birmingham

\subsection{6/spcare-2020-PCC.124}

Background Continuous subcutaneous infusions (CSCIs) are often used in the palliative care setting where patients require regular medication but the oral route is not available. Symptoms may include debilitating pain, nausea or seizures so medication should be started promptly after clinical review. While there is no clear definitive time frame for these, we would aim for infusions to begin within 2 hours, with anything above 4 hours an unacceptable delay.

This study took place at the Queen Elizabeth Hospital, Birmingham UK and its purpose was to determine whether CSCIs are being commenced promptly after being prescribed.

Methods Using the electronic data system, we looked at all of the patients to have a McKinley infusion commenced, and who were referred to the palliative care team during the period 1 April - 31 July 2018.

Results 104 patients fitted the inclusion criteria. 45\% of infusions were commenced within 2 hours and a total of $74 \%$ were commenced within 4 hours. The mean time to start (TTS) was 225 minutes (range 14-1581 minutes). There were 9 infusions that took over 600 minutes (10 hours) to be commenced. These affect mean calculations considerably.

Discussion One common reason cited by ward staff was the prescriber not informing nurses that they had prescribed a CSCI. We noted that a prescriber can prescribe remotely from another ward in the hospital, giving barriers to good verbal handover to nurses. Other reasons cited include prescriptions being erroneous and having to be re-prescribed, or having to wait for Mckinley pumps to be delivered by equipment stores. This study highlights an important patient experience issue for individuals towards the end of life, and additionally for prescribers. The very best medical knowledge and nursing skill can be undone by an avoidable delay in the commencement of a basic infusion.

\section{INAPPROPRIATE USE OF NALOXONE IN A HOSPITAL SETTING COMPROMISING PATIENT SAFETY: A QUALITY IMPROVEMENT PROJECT}

Maria Mandel, Jennifer Palfrey, Ruth Caulkin. Chelsea and Westminster Hospital

10.1136/spcare-2020-PCC.125

Background Life threatening opioid toxicity is a rare but recognised complication of opioid use. In 2014, NHS England released a patient safety alert on inappropriate prescribing of naloxone in patients with chronic opioid use, citing 2 fatal cases. A retrospective audit (2017) of naloxone use in an acute London hospital demonstrated that $90 \%(18 / 20)$ of administrations did not meet recommended standards. This prompted a quality improvement project to improve practice.

Methods A trust guideline was developed using the Palliative Care Formulary and UK Medicines Information naloxone evidence review. This was disseminated through education sessions and email updates. An alert was created on the trust electronic prescribing system. Following this, repeat data was collected retrospectively over 3 months for all adult hospital inpatients (excluding ITU and ED) administered naloxone. Electronic clinical notes were reviewed for: reason for naloxone use, respiratory rate, oxygen saturation, level of consciousness and dose given.

Results Repeat audit (2019) demonstrated 3 administrations of naloxone, of which 2 did not meet the guideline standard an $89 \%$ reduction in inappropriate administrations of naloxone compared to baseline. The dose which was appropriately administered was also of the recommended dose.

Conclusion/Discussion There has been a marked decrease in inappropriate administrations of naloxone in patients with chronic opioid use since the intervention. However, continued work is needed as reduced conscious level often triggered naloxone use despite absence of respiratory depression or hypoxia.

Recommendations Continued dissemination of the guideline, particularly with rotation of staff.

Ensure that the prescribing alert is maintained on future prescribing systems.

\section{Psychosocial | posters $106-108$}

\section{ROLES AND EXPERIENCES OF NURSES WHEN MEETING THE PSYCHOLOGICAL NEEDS OF PATIENTS RECEIVING PALLIATIVE CARE}

Adeoye Adenike, Cara Bailey, Alistair Hewison, Christopher Wagstaff. University of Birmingham

\subsection{6/spcare-2020-PCC.126}

Background Patients receiving palliative care experience psychological distress towards the end stage of their life and though some cope effectively, some do not. The psychological needs of these patients are sometimes overlooked by healthcare provider because physical symptoms such as pain, vomiting and respiratory distress are prioritised. Nurses are well positioned to recognise psychological distress and help patients manage it leading to a better experience at the end of life. 